\title{
Life Story of Chinese College Students with Perfectionism Personality: A Qualitative Study Based on a Life Story Model
}

\author{
Min $\mathrm{Ma}^{1} \&$ Fei $\mathrm{Zi}^{2}$ \\ ${ }^{1}$ Department of Psychology, Central University of Finance and Economics, Beijing, China \\ ${ }^{2}$ Department of Psychology, Beijing Forestry University, Beijing, China \\ Correspondence: Min Ma, Department of Psychology, Central University of Finance and Economics, Beijing, \\ China. Tel: 86-185-1133-2213. E-mail: Catherine.mamin@gmail.com
}

\author{
Received: February 19, 2014 Accepted: November 3, 2014 Online Published: January 27, 2015 \\ doi:10.5539/ies.v8n2p38 \\ URL: http://dx.doi.org/10.5539/ies.v8n2p38
}

\begin{abstract}
This manuscript aims to explore and delineate the common characteristics of college students with perfectionism, to promote an in-depth understanding of dynamic personality development of perfectionists from the views of life story model proposed by McAdams (1985). The researchers adopted a narrative qualitative research method. The life stories of respondents who had a strong tendency of perfectionism were analyzed. We found out that participants experienced intensive feelings of superiority and inferiority due to fluctuations of academic performance. Most respondents tended to use negative tone in describing their interpersonal relationship. Respondents hold high expectations for their future. Moreover, they tended to believe that some supernatural power controls the world and the lives. Themes of life story of perfectionists normally focused on three themes: self-control, status and success, and love and friendship. The perfectionists with negative tone usually show that they are only pursuing a powerful energy, a sense of control, and status.
\end{abstract}

Keywords: qualitative study, perfectionism, narrative analysis, life story

\section{Introduction}

A large number of quantitative studies have been done on perfectionism (e.g. Flett, Hewitt, \& Singer, 1995; Frost, Heimberg, Holt, Mattia, \& Neubauer, 1993; Black \& Reynolds, 2013). However, based on our experiences as psychological counselors, the authors of the present article realized that some deep characteristics and reasons of perfectionism are still in need of further exploration. We believe that a qualitative method will be more appropriate. Qualitative study is good at probing into the interactions between environment and individuals, drawing conclusions based on the analysis of original experiential materials. Also, qualitative method is more likely to depict a whole picture of the process of dynamical personality development of college students with perfectionism.

\subsection{Life Story}

In 1980s, psychologist Sarbin (1986) posted the concept of "narrative psychology", which is a psychological view or position referring to a concern for "narrative human behavior" that how human behavior is organized by the story and how individuals could create meaning by themselves. Also, there emerged some studies on personality with view of narrative and a series of models of Life Story was proposed (McAdams, 2008; Bauer, McAdams, \& Pals, 2008).Distinct narrative theorists suggested different theories of life stories such as script theory (Tomkins, 1987), identity life story model (McAdams, 1985), and dialogical self theory (Hermans, Kempen, \& Van Loon, 1992). McAdams (2008) put great emphasis on identity. He contended that "people living in modern societies begin, in late adolescence and young adulthood, to construct their lives as evolving stories that integrate the reconstructed past and anticipate the future in order to provide life with some semblance of unity and purpose" (p. 243). Integrative personality framework views personality in terms of three different levels: dispositional traits, characteristic adaptations and integrative life stories. Life stories are "based on empirical fact but also go beyond fact as imaginative renderings of past, present, and future, to make one's life in time into a meaningful narrative" (McAdams, Diamond, de St. Aubin, \& Mansfield, 1997, p. 679) and are also "those internalized and evolving self-narrative that people construct to make sense of their lives in time" (McAdams, 2011, p. 99). 
McAdams (1996) pointed out that life story should be analyzed in terms of seven features: narrative tone, imagery, theme, ideological setting, nuclear episode, imagoes and the endings. The present study is based on the McAdams' life story model of identity (McAdams, 1993, 1996). (a) Narrative tone is the emotional tone or attitude revealed in the story. (b) Imagery makes the narrative idiosyncratic by the sound, the smells and the tastes, the metaphors, and similes the author creates.(c) The themes manifest the goal the characters pursue in narrative and these goals unfold the characters' motivation. McAdams (1985) suggested that communion and agency (Note 1) are the two central super ordinate thematic clusters in the life narratives. The four agency themes are: (1) self-mastery, (2) status/victory, (3) achievement/responsibility, and (4) empowerment. The four communion themes are: love/friendship, (6) dialogue, (7) caring/help, and (8) unity/togetherness (McAdams, 2001). According to this, we can analyze which themes are shown in each episode of a life story. (d) Ideological settings convey the characters' religious, ethical, and political beliefs and values. (e) Nuclear episodes pertain to the crucial scenes or important point of the narrative (e.g., high points, low points, beginning points, ending points, and turning points). "These reconstructed scenes typically affirm self-perceived continuity or change in the Me over time" (p. 309).Also, according to these scenes we could analyze the needs. Maslow (1943) pointed out that the most fundamental and four basic layers of the pyramid contain what he called "deficiency needs": esteem, friendship and love, security, and physical needs. The higher level need is self-actualization. Maslow (1970) described self-actualization as the "full use and exploitation of talents, capabilities, potential, etc." (p. 150). The self-actualization is on the top layer of the pyramid. If we understand perfectionism as holding a high standard and pursuing/striving for the fulfillment of the self-expectation, it seems that self-actualization is a positive approach to be a perfectionist. (f) Imagoes are idealized personifications that represent the main character of the narrative. If we understand imagoes from the perspective of the self psychology (Kohut \& Wolf, 1978; Kohut, 1984), these imagoes could be self objects of a certain person. Self objects are objects that we view or experience as part of ourselves. Thus, imagoes could be important objects in one's life story. According to Kohut and Wolf (1978), there are two kinds of self objects: the mirroring self ojbect and the idealized parent imago. The first type refers to "those who respond to and confirm the child's innate sense of vigour, greatness and perfection"; and the second type describes "those to whom the child can look up and with whom he can merge as an image of calmness, infallibility and omnipotence" (p. 414). Based on the quality of the interactions between the self and its self objects in childhood, the self "will emerge either as a firm and healthy structure or as a more or less seriously damaged one"(p. 414). (g) Endings: the generativity script. Ending means a new beginning. "The generativity script is that part of the life story that concerns how the adult generates, creates, nurtures, or develops a positive legacy of the self, to be offered to subsequent generation" (p. 309). Therefore, "Me" is existed beyond the spatial limitation of the life.

\subsection{Perfectionism}

The research of perfectionism can be traced back to Adler (1956) who is the founder of individual psychology. Among human motivations, Adler believed that pursuing perfection is the purest and the most essential one. However, according to literatures on perfectionism, the following two points of view are commonly seen in the study: perfectionism is explained by negative characteristics; or perfectionism is both negative and positive based on the perspective of dichotomy (Frost et al., 1993). The positive elements of perfectionism include holding standards and being orderly and low-inferiority (Johnson \& Slaney, 1996). The negative elements of perfectionism are generally seen as follows: stubbornly insisting on the belief that negative events will repeatedly happen; suffering from "should" principle (Burns, 1980); constantly setting high objectives and accordingly suffering from frustration (Pacht, 1984); never obtaining enough sense of achievements despite success (Weisinger \& Lobsenz, 1981); and strong sense of inferiority (Ashby, 1996). In terms of the orientation and the contexts, perfectionism can be divided into three dimensions: self-oriented perfectionism, other-oriented perfectionism, and social prescribed perfectionism (Hewitt \& Flett, 1991b). The scales and the questionnaires measuring perfectionism can be divided into two types: the one-dimensional and the multi-dimensional (Frost, Marten, Lahart, \& Rosenblate, 1990). Corresponding to the positive elements and the negative elements of perfectionism, $\mathrm{Zi}(2007,2009)$ developed two scales of perfectionism questionnaires. Thus, we can clearly recognize the subtypes (positive and negative) of perfectionism.

As stated above, the term perfectionism has been defined in various contexts/dimensions. Recently, the construct of perfectionism is further explored and studied. A through study (Stairs, Smith, Zapolski, Combs, \& Settles, 2012) clarifies the specific unidimensional personality constructs that contribute to perfectionistic behavior based on 15 existing measures of perfectionism. They collected and sorted 15 scales, and then developed a new scale called "the measure of constructs underlying perfectionism" including 9 dimensions of personality traits relevant to perfectionism. These dimensions are as follows: high standard, order, details and checking, 
dissatisfaction, perceived pressure from others, perfectionism towards others, reactivity to mistakes, satisfaction, and black and white thinking.

The experience of childhood and parent-children interaction plays a key role in the formation of the perfectionistic personality. Based on the two dimensions of warmth and demandingness, Baumrind (1989) proposed four parenting styles: authoritative, authoritarian, permissive, and indifferent. Authoritative parenting, characterized by a child-centered approach, is a balanced style. They take care of children's feeling and communicate with them. Authoritarian parenting, featured by the compliance to parents' rules, regulations, and expectations, allows little democratic dialogue between parent and child. Improper parenting styles are partly attributed to the development of perfectionism (Flett et al., 1995). Furthermore, parental perfectionistic characteristics would have an impact on the development of perfectionistic characteristics in children(Azizi \& Besharat, 2011).

Perfectionism is closely related to the mental health of individual (Ablard \& Parker, 1997). The extreme perfectionismis often associated with various personality disorders and neurological disorders (Hewitt \& Flett, 1990),such as eating disorders (Sassaroli et al., 2011), depression (Black \& Reynolds, 2013; Terry-Short, Owens, Slade, \& Dewey, 1995), compulsive personality disorder (Moretz \& Mckay, 2009; Wu \& Cortesi, 2009), anxiety (Eum \& Rice, 2011), and social phobia (Hewitt \& Flett, 1991a). Some studies also suggest that self-concealment and contingent self-worth mediate the relationship between perfectionism and psychopathology (DiBartolo, Li, \& Frost, 2008). Other researchers found that "concern over mistakes" accounted for the most of the variance in the relationship of perfectionism to the forms of psychopathology (depression, anxiety disorders and eating disorders) (Sassaroli et al., 2008).

\subsection{Life Story and Perfectionism}

There are rarely studies which focus on the life stories of perfectionists. Past research only explored the relationships between dispositional traits (especially Big Five personality traits) and narrative identity(McAdams et al., 2004).Although there was a study about the relationship between perfectionism, agency and communion, which suggested that perfectionists are strongly motivated by agentic concerns(Mackinnon, Sherry, \& Pratt, 2013), it merely put emphasis on relationships between personality traits and the themes of life stories rather than depicted a whole picture of the life stories of perfectionist. Only in the latter situation can we have a deep understanding about these tendencies of the themes, tones and imagery of life stories. After we have a deep understanding about the life stories of perfectionism, it is possible to shed light on future psychological counseling and treatment.

\section{Method}

\subsection{Participants}

The sample consisted of college undergraduates and graduate students, a total of nine participants (5 males; 4 females). Participates ranged in age from 19 to 28 years ( $M=24$ years). Five of them major in science and technology, and the rest of them major in social sciences. They all more or less self-nominated or were nominated by others as "perfectionists".

\subsection{Procedures}

These respondents were firstly evaluated by experts and were then interviewed for one hour and a half. The subtype of the interviewees is determined by ZNPQ (Zi, 2007) and ZPPQ (Zi, 2009). A survey (Zi, 2007) shows that if the percentage is higher than $95 \%$ or the total score is higher than 149 , the interviewee possesses obvious features of negative perfectionism while $85 \%-94 \%$ or $134-149$ evidences certain tendency towards negative perfectionism. According to this, there are six interviewees reveal certain tendency towards negative perfectionism, while three interviewees are evaluated as the positive perfectionists. The demographic of respondents are described in Table 1.

All of the interviews except the first interview session were recorded based on the agreement of the subjects. Then, the recorded interviews were transcribed into text (a total of 120 thousand words) and the data was analyzed and coded by NVIVO 9.2 software. The author coded all data using coding system for agency and communion (Table 2). Then, after sorting, summarizing, and coding, we organized the whole coherent life story of every interviewee. As the final step, each part of the life stories of 9 respondents were compared, analyzed, and discussed. 


\subsection{Materials}

\subsubsection{Negative Perfectionism Questionnaire (ZNPQ)}

ZNPQ (Zi, 2007) includes five dimensions, namely, "hesitation" "fear of failure" "over-scrupulous " "excessive plan and control " and "high objective and strict norm". Cronbach' $\alpha$ among dimensions is respectively $.82, .78, .83, .76$, and .75 .

\subsubsection{Positive Perfectionism Questionnaire (ZPPQ)}

ZPPQ (Zi, 2009) includes three dimensions: "positive self-expectation", "positive logic" and "positive self-evaluation". The Cronbach's $\alpha$ is respectively $.87, .76$, and .79.

\subsubsection{Life Story Interview}

As a narrative study, we collected data through semi-structured interviews. The questions asked in the interviews were designed according tothe model of the life story interview proposed by McAdams (1995). It consisted of open-ended questions regarding a variety of aspects according to McAdams' (1985) life story model: life chapters, specific scenes (including peak experience, nadir experience, turning point experience, earliest memory, significant childhood memory, and significant adolescent memory), important persons, future chapters, tension and conflicts, personal ideology, and dominant theme of the story. Given that the average age of the respondents is 24 years old, we focused on analyzing the periods from birth to late adolescence and young adulthood.

Table 1. Demographics of participants

\begin{tabular}{lllllll}
\hline No. & Alias & Gender & Year of birth & Age & Subject & Type \\
\hline A & Meng & F & 1988 & 20 & Science \& technology & NP \\
B & Yan & F & 1988 & 20 & Social science & NP \\
C & Yun & F & 1985 & 24 & Social science & NP \\
D & Cong & M & 1984 & 25 & Social science & NP \\
E & Guo & F & 1984 & 24 & Science \& technology & NP \\
F & Gong & M & 1990 & 19 & Social science & NP \\
G & Mu & M & 1984 & 26 & Science \& technology & PP \\
H & Zi & M & 1982 & 28 & Science \& technology & PP \\
I & Jin & M & 1984 & 26 & Science \& technology & PP \\
\hline
\end{tabular}

Note. $\mathrm{F}=$ Female; $\mathrm{M}=$ Male; $\mathrm{NP}=$ Negative Perfectionism; $\mathrm{NT}=$ Negative Tone; $\mathrm{PP}=$ Positive Perfectionism.

Table 2. Themes and definitions

\begin{tabular}{ll}
\hline Themes & Definitions \\
\hline Agency & \\
Code 1-SM & $\begin{array}{l}\text { Strive successfully to master, control, enlarge, or perfect the self. The individual } \\
\text { strengthens the self through forceful or effective action, thought, or experience. Two } \\
\text { expressions of the theme: attaining a dramatic insight into the meaning of his or her } \\
\text { life; experiencing a greatly enhanced sense of control. }\end{array}$ \\
Code 2-SV & $\begin{array}{l}\text { Attain a heightened status or prestige among his or her peers, through receiving } \\
\text { special recognition or honor or winning a contest or competition. } \\
\text { Code 3-AR }\end{array}$ \\
$\begin{array}{l}\text { The person reports substantial success in the achievement of tasks, jobs, instrumental } \\
\text { goals, or in the assumption of important responsibilities. } \\
\text { Code 4-EM }\end{array}$ & $\begin{array}{l}\text { The subject is enlarged, enhanced, empowered, ennobled, built up, or made better } \\
\text { through his or her association with someone or something larger and more powerful } \\
\text { than the self. }\end{array}$ \\
\hline
\end{tabular}


Communion

Code 5-LF

Experience an enhancement of erotic love or friendship toward another person.

Code 6-DG

Experience a reciprocal and non-instrumental form of communication or dialogue with another person or group of others.

Code $7-\mathrm{CH}$

The individual reports that he or she provides care, assistance, nurturance, help, aid, support, or therapy for another, providing for the physical, material, social, or emotional welfare or well-being of the other.

Code 8-UT

Communal idea of being part of a larger community.

Note. The information in the table is based on the paper entitled "Coding Autobiographical for Themes of Agency and Communion"(McAdams, 2001). SM=Self-mastery, SV=Status/Victory, $\mathrm{AR}=$ Achievement/Responsibility, $\mathrm{EM}=$ Empowerment, $\mathrm{LF}=$ Love/Friendship, $\mathrm{DG}=\mathrm{Dialogue}, \mathrm{CH}=\mathrm{Caring} / \mathrm{Help}$, $\mathrm{UT}=\mathrm{Unity} /$ Togetherness.

\subsection{Analysis}

To analyze the themes of agency and communion in the interviewees' life story, we adopted the coding system developed by McAdams (2001). According to the semi-structured interviews, we explored the themes in every aspect, especially in specific scenes. In our line of research, these specific scenes include six episodes: peak experience, nadir experience, turning point experience, earliest memory, significant childhood memory, and significant adolescent memory. The scoring unit is the episode itself. According to McAdams (2001, p.2), we code each episodefor the presence (score +1 ) or absence (score 0 ) of eight different themes, four under the heading of agency and four under the heading of communion. Then, we summed scores of agency and communion respectively for each episode. Thus, the highest score of agency/communion for a given episode would be " 4 ", and the lowest score would be " 0 ". Finally, we added the total score of agency/communion for each response.

\section{Results}

\subsection{Narrative Tone}

Narrative reveals the emotion and attitude in the story. We analyzed the statements that the respondents used to describe their life stories. Based on the data collected, if more than $50 \%$ of the statements revealed negative emotion or attitude, a certain respondent will be categorized in the group of negative tone. Six respondents with negative perfectionism tended to use negative tone to present their life stories. All of respondents with positive perfectionism described their life stories with positive tone.

\subsection{Imagery of Life Story}

\subsubsection{Life Chapters}

Respondents tended to divide their life-story chapters based on the different stages of their education, the major concerns of which are related to interpersonal issues and academic performance. Also, 7 (respondents B, C, D, E, F, G, and I) of nine participants had repeated experience of the strong fluctuations in academic performance. Perfectionistic respondents were most likely to show a negative tone when narrating interpersonal relationship. They were more likely to describe their lives as isolated and hard to find true friendship (e.g., A, B, C, E, and F). In life stories of perfectionists with most negative tone, interpersonal relationships were usually a core issue perplexing them. One possible reason for it is that they focused a great deal on themselves, and were sensitive, egocentric, paying no attention to the outer world. We will go back to this topic in the section of discussion.

\subsubsection{Specific Scenes}

This part of the interview mainly related to six items: peak experience, nadir experience, turning point experience, earliest memory, significant childhood memory, and significant adolescent memory. Interviews with respondent $A$ showed that she could feel peak experience when she comes across a beautiful natural view. Respondents B, D, and E had better feelings when they achieved excellent academic results, which fulfill the need for high esteem. However, great academic performance made respondent I feel that he gave play to his potential. Respondent $\mathrm{C}$ always complained that she had received little love, which reveals that she desired a sense of safety. F and G asserted that they had no peak experience. However, they believed that they were in the process of pursuing self-actualization. Respondent $\mathrm{H}$ successfully met the need of self-actualization. He 
experienced a peak point when he achieved high academic achievement or successfully helped others achieve better results. We found that 2 of the three perfectionists with positive tone were to meet the needs of growing or self-actualization, while perfectionists with negative tone were generally motivated by esteem and love.

\subsubsection{Important Persons}

In the life-stories of perfectionists, at least one "perfect image" appears which thus encourage the respondents to pursue their "perfect states". For instance, respondent A expressed her worship of excellent women. Respondents $\mathrm{B}$ and $\mathrm{C}$ stated that their mothers had high self-esteem and were independent. Respondent $\mathrm{D}$ had a sense of absolute dependence on authority. At the same time, he also wanted himself to be a luminary to gain senses of safety and control. Respondent E had a great respect of Premier Zhou (Chinese former Premier Enlai Zhou), while respondent $\mathrm{F}$ admired those who achieved academic and career successes. Both respondents $\mathrm{G}$ and $\mathrm{H}$ viewed their fathers as holding high moral standards and possessing excellent characteristics. Respondent I showed his respect and fear to the Creator(similar to the concept of God in western culture).

\subsubsection{Future Chapters and Personal Ideology}

On the future and personal ideological level, all of the respondents showed high expectations for their future. Respondent A hoped that she could become a powerful and excellent woman in the future. She said, "Women should have their own choices and life-styles instead of only fostering children after getting married" (Individual Interview, December 15, 2008). Respondent A thought that she had always obeyed her parents, and didn't dare to push boundaries. She lived with constant pressure to be a "good girl". It is possible that, having been deprived lots of rights and the ability to think independently when she was young, she desperately desired the power.

Most respondents (A, B, C, D, E, G, and I) believed that some kinds of supernatural powers control the universe and the life. Respondent B labeled herself as a superstitious person. She remembered that as she was in high school, she worshiped Buddha at temples before taking exams. She believed that it was this worship that blessed her to keep on ranking No. 1 in her class. Moreover, she required herself to eat a special kind of food before certain exam. She believed that "only after eating this special food could I obtain an excellent result" (Individual Interview, December 18, 2008). Meanwhile, she acknowledged that "even I don't have an accurate religious belief, I usually tell myself that God would prefer a good child and then encourage myself to be a good girl"(Individual Interview, December 18, 2008). B also asserted that she believed in karma and accordingly, a high standard of morality should be kept. In addition to cultural influences, it is possible to assume that perfectionists tend to believe that a supernatural power controls the universe and life.

\subsubsection{Tension and Conflicts}

So far as the pressure and the problems are concerned, respondents in the present study reported many of the symptoms suggesting personality and neurological disorders. For instance, Respondent D was pretty worried about his health condition and visited doctors frequently. It happened almost once every six months in the last six years (initially diagnosed by his doctor as DSM-IV 300.7 Hypochondriasis). Respondent E was extremely nervous when she saw her advisor. Her neck trembled when she felt nervous. She reported that she felt nervous when she saw some of her classmates, which persisted for the last three months. After checking into a hospital, no physical disease (initially diagnosed as social phobia) was diagnosed. Respondent $\mathrm{F}$ reported that he was distractible and had a strong sense of loneliness that lasted for the whole year of 19 years old. Respondent $C$ was unable to sleep well for the last four to five years, and also had some other symptoms, such as headache, depression, and a trouble with interpersonal relationships. She was unsatisfied with her state at that time. It was not only because of the lack of the desired love that she had never received but also because she got more worried and irritable due to the lack of love which could ease her pain and anxiety. Here, the "lack of love" means "lack of unconditional love". She said, "I desperately need energetic and unlimited love. Mum's love makes me so hard to breath. I was always working very hard and achieved good academic results to return this love. I was indulged into Mum's expectation. I don't know what kinds of love I truly need...maybe some unconditional love" (Individual Interview, June 5, 2009).So being strict with herself and constantly pursuing perfection could ease her sense of loss. Unfortunately, at the same time, she felt accumulated anxious and painful. She lived in a state of serious inner conflict.

\subsection{Dominant Theme of the Story}

According to Table 3, the theme of life stories of perfectionists focused on self-control (code1), status and success (code2), and love and friendship (code5). Among the two major themes (agency and communion), agency was more dominant in their life (Table 4). 
Table 3. Frequencies and coding examples for themes of life story

\begin{tabular}{lll}
\hline $\begin{array}{l}\text { Coding } \\
\text { Category }\end{array}$ & Frequency & Examples \\
\hline Code 1-SM & $90(36.6 \%)$ & $\begin{array}{l}\text { Eg1. "I will not associate my study with my [health], and I will never fight for } \\
\text { study at the cost of my body health" (Respondent D, Individual Interview, August } \\
\text { 13, 2009). } \\
\text { Eg2. "After that [a humiliated thing], I work hard on my study. I don't allow } \\
\text { myself to commit even a small error" (Respondent C, Individual Interview, June } \\
5,2009) .\end{array}$
\end{tabular}

Code 2-SV 49(19.9\%) Eg1. "I am the leader [of my class], and I always rank No.1 in my class" (Respondent A, Individual Interview, December 8, 2008).

Eg2. "[I am good at] mathematics. I was praised a lot by my mathematical teacher" (Respondent E, Individual Interview, December 7, 2009).

Code 3-AR 18(7.3\%) Eg1. "I must keep my promise. It's my responsibility and I should do it well" (Respondent G, Individual Interview, August 10, 2009).

Eg2. "I recognize my value in this team. I have contributed too much to this team" (Respondent H, Individual Interview, December 4, 2009).

Code 4-EM 11(4.5\%) Eg1. "I admire doctor...They must have high rank/grade, and I weigh too much on it" (Respondent D, Individual Interview, August 13, 2009).

Eg2. "My father is the guider of my life direction...He gives me a sense of safe" (Respondent D, Individual Interview, August 20, 2009).

Code 5-LF 44(17.9\%) Eg1. "I make a good friend in my junior middle school...I enjoy the feeling of communicating with her" (Respondent A, Individual Interview, December 8 , 2008).

Eg2. "I desire to fall in love with somebody" (Respondent C, Individual Interview, June 5, 2009).

Code 6-DG 16(6.5\%) Eg1. "I should actively communicate with others. They have many good ideas" (Respondent F, Individual Interview, December 17, 2009).

Eg2. "My father always shares ideas with me... [In this way,] I think I know him very well" (Respondent H, Individual Interview, December 4, 2009).

Code 7-CH 5(2.0\%) Eg1. "I feel happy when I help others" (Respondent H, Individual Interview, December 4, 2009).

Eg2. "My father gives plentiful love to us. He supports us and helps us to make our dreams come true" (Respondent H, Individual Interview, December 4, 2009).

Code 8-UT 13(5.3\%) Eg1. "I feel extremely happy when I see the sea. I love that feeling. It seems that, uh ... I merge into the whole nature" (Respondent A, Individual Interview, December 15, 2008).

Eg2. "I am very glad to stay with my grandma. She is so nice and tolerant" (Respondent F, Individual Interview, January 7, 2010).

\begin{tabular}{lccc}
\hline Note. & $\mathrm{SM}=$ Self-mastery, & $\mathrm{SV}=$ Status/Victory, & $\mathrm{AR}=$ Achievement/Responsibility, \\
$\mathrm{LF}=$ Love/Friendship, $\mathrm{DG}=$ Dialogue, $\mathrm{CH}=$ Caring/Help, $\mathrm{UT}=$ Unity/Togetherness.
\end{tabular}


Table 4. Coding results of themes of life story

\begin{tabular}{|c|c|c|c|c|c|c|c|c|c|c|c|c|c|c|c|c|c|c|}
\hline \multirow[t]{2}{*}{ Themes } & \multicolumn{2}{|l|}{ A } & \multicolumn{2}{|l|}{$\mathrm{B}$} & \multicolumn{2}{|l|}{$\mathrm{C}$} & \multicolumn{2}{|l|}{$\mathrm{D}$} & \multicolumn{2}{|l|}{$\bar{E}$} & \multicolumn{2}{|l|}{$\mathrm{F}$} & \multicolumn{2}{|l|}{ G } & \multicolumn{2}{|l|}{$\mathrm{H}$} & \multicolumn{2}{|l|}{ I } \\
\hline & $\mathrm{Ag}$ & Co & $\mathrm{Ag}$ & $\mathrm{Co}$ & $\mathrm{Ag}$ & Co & $\mathrm{Ag}$ & $\mathrm{Co}$ & $\mathrm{Ag}$ & $\mathrm{Co}$ & $\mathrm{Ag}$ & Co & $\mathrm{Ag}$ & $\mathrm{Co}$ & $\mathrm{Ag}$ & $\mathrm{Co}$ & $\mathrm{Ag}$ & Co \\
\hline LC & 1 & 3 & 3 & & 2 & 1 & 1 & & 2 & 2 & 3 & & 3 & 2 & 2 & 1 & 2 & \\
\hline CE-PE & & 1 & 1 & & & 1 & 1 & & 1 & & & 1 & 1 & & 1 & 1 & 1 & \\
\hline CE-NE & & 2 & 1 & 1 & & 1 & 1 & & 2 & & & & 1 & 1 & 1 & 1 & 1 & 1 \\
\hline CE-TP & & 1 & 1 & & & 1 & 1 & & 1 & & 2 & & & & 2 & & 1 & \\
\hline CE-EM & 1 & & 1 & 1 & & 1 & 1 & & & 1 & & 1 & 1 & & 1 & & 1 & \\
\hline CE-ICS & & 3 & 1 & & 1 & 2 & 1 & & 1 & 1 & & 1 & 2 & & 1 & & 1 & 1 \\
\hline CE-IAOS & & 3 & 1 & & 2 & 1 & 2 & & 1 & 1 & & 1 & 1 & & & 1 & & \\
\hline CE-IAUS & & & & & & & 2 & & & & 1 & 1 & 1 & & & 1 & & 2 \\
\hline IP & 1 & 2 & 2 & 1 & 1 & 1 & 2 & & 2 & 2 & 2 & 2 & 3 & & 2 & 2 & 1 & 1 \\
\hline FLS & 1 & & 1 & & 1 & & 2 & & 1 & & 2 & & 3 & & 2 & & 2 & \\
\hline LC & 1 & 1 & 1 & 1 & & 1 & & & & & 1 & & 1 & & 2 & & & \\
\hline PI & 1 & & 2 & & & 1 & 2 & & 1 & & & & 1 & & 1 & & 1 & 1 \\
\hline LT & & & 3 & & & & 1 & & 2 & & & & & & & & & \\
\hline Sum & 6 & 16 & 18 & 4 & 7 & 11 & 17 & 0 & 14 & 7 & 11 & 7 & 18 & 3 & 15 & 7 & 11 & 6 \\
\hline DT & $\mathrm{Co}$ & & $\mathrm{Ag}$ & & $\mathrm{Co}$ & & $\mathrm{Ag}$ & & $\mathrm{Ag}$ & & $\mathrm{Ag}$ & & $\mathrm{Ag}$ & & $\mathrm{Ag}$ & & $\mathrm{Ag}$ & \\
\hline
\end{tabular}

Note. $\mathrm{Ag}=\mathrm{Agency}$; $\mathrm{Co}=$ Communion; $\mathrm{LC}=$ Life Chapter; $\mathrm{CE}=\mathrm{Critical}$ Events; $\mathrm{PE}=$ Peak Experience; $\mathrm{NE}=\mathrm{Nadir}$ Experience; TP=Turning Point; EM=Earliest Memory; ICS=Important Childhood Scene; IAOS=Important Adolescent Scene; IAUS=Important Adult Scene; IP=Important Persons; FLS=Futures of Life Story; LC=Life Challenge; PI=Personal Ideology; LT=Life Theme; DT=Dominant Type.

\section{Discussion}

We observed that the negative perfectionists were likely to describe their life stories with negative tone, in contrast, positive perfectionists tended to use positive tone to narrate their life stories. Based on the factors of ZNPQ ( $\mathrm{Zi}, 2007)$ and ZPPQ ( $\mathrm{Zi}, 2009)$, it is possible that negative tone (sad, fear, anxiety...) is closely related to fear of failure, high objective and strict norm, while positive tone has strong relationship with positive self-evaluation, self-logic and self-expectation. That's the difference between perfectionists' cognitive styles of avoiding failure and pursuing success when they desire to achieve high standard.

Regarding to the life chapters, most of the participants had repeated experience of the strong fluctuations in academic performance. We supposed that these fluctuations provoked intense feelings of superiority or inferiority. For perfectionists, these feelings tended to be accompanied by a sense of achievement and provoke more intense desire for strengthening their tendency of perfectionism. However, positive perfectionists tended to analyze the reasons, try harder, and adjust their goals and expectations to a suitable level, without experiencing a strong sense of superiority or inferiority. This gave us some implication for education. It would be better if we do not excessively emphasize the scores. The key point is to find out the mistakes and correct them and aware of the academic performance is only one aspect of the evaluations of students. Although adversity is an aspect that is vital to students' learning process, it should not at the expense of students' self-esteem.

We used the theory of Maslow's hierarchy of needs (Maslow, 1970) to discuss the peak experience of specific scenes. According to the data, we found out that perfectionists with positive tone tended to pursue the needs of growing or self-actualization, while perfectionists with negative tone were motivated by esteem and love. Based on the results, we supposed that negative-tone-perfectionists pursue deficiency needs and positive-tone-perfectionists try to achieve self-actualization reversely.

In terms of the development of perfectionism, many factors contribute to this personality facet. There is one common character when we focus on the important persons and personal ideology of perfectionists: they all have at least one ideal image, which we can view them as self objects in the context of self psychology (Kohut \& Wolf, 
1978; Kohut, 1984). Firstly, We noticed that some of the participants showed strong dependence on these "ideal images", either in need of protection/safety or making oneself satisfied to have such a person or an abstract person around him/her. This probably corresponds to the self objects of "idealized parent imago", which has an internal monologue: "you are so perfect; I am a part of you". Secondly, we observed that all of the participants referred that their parents or custodians were strict with them. As far as life stories (early adulthood) are concerned, if the parenting style was strict/"authoritarian", it seems that it played a decisive role in the formation of perfectionism. There were studies which suggested that parenting styles and parental perfectionistic would partly attribute to the development of perfectionism (Ablard \& Parker, 1997; Flett et al., 1995). Although achievement goals of parents could affect academic performance of their children, it could also predict which students might be at risk for adjustment problems and future underachievement (Ablard \& Parker, 1997). Admittedly, events/environment of childhood and adolescence could affect integration and formation of personality. Thirdly, we also found most of the respondents believed that some kinds of supernatural powers control the universe and the life. Although a perfect image is so vital to a perfectionist, a pure perfect image does not exist in daily life. So we supposed that when there is conflict between the expectation and the reality, perfectionists have a sense of losing control, which indeed points to a sense of helplessness or fear. This extreme helplessness and fear can only be consoled by the supernatural power that gives them a sense of security and control. Additionally, a supernatural power gives perfectionists an opportunity to be close to a perfect image that cannot be seen in the real world. In sum, if we view some vital persons or objects as important self-objects, we would like to emphasize that the analysis of the relationships between self and self-objects (especially the ideal image) could be a way to solve the problems met by perfectionists.

The result suggested that many of the symptoms reported by the respondents linked to the personality and neurological disorders. As stated in the literature, the extreme perfectionists are often associated with various personality disorders, such as the narcissistic personality disorder and the obsessive-compulsive personality disorder (Ablard \& Parker, 1997; Hewitt \& Flett, 1990). And some neurological disorders such as anxiety, depression, social phobia, somatoform disorders, and eating disorders are also included (Hewitt \& Flett, 1991a; Terry-Short, Owens, Slade, \& Dewey, 1995). Thus, our research results fit the studies stated above. Regarding to the tension and conflicts, "Lack of love" was the vital feeling of respondent C. The loss of love in childhood aroused her desire for compensation. Obviously, she desired perfect love. However, on the other hand, she doesn't believe that that kind of love really exists. So she always put herself in a dilemma of extreme expectation and extreme disappointment. It was a cycle of finding love, feeling unsatisfied and losing love. She had problem with her intimate relationship. Just as the neurosis theory of Horney (1992) suggests, it is more likely a release of basic hostility and inner conflict. So it would be better to analyze the unconscious or pent-up hostility and conflict, which is a way to conduct the treatment. And it is also a vital way to re-integrate conflicting personalities.

Especially, we also noticed that the respondents with negative tone were more likely in trouble with personality and neurological disorders. This result corresponds to a study conducted by McAdams et al. (2004). The study revealed that neuroticism was positively associated with an emotionally negative life-narrative tone (McAdams et al., 2004). We referred in the foregoing text that negative perfectionists tended to use negative tone to depict their life stories and positive perfectionists behaved reversely. Thus, it makes sense to study perfectionism from the perspective of dichotomy, especially in the context of narrative tone of life stories.

We found out that the theme of agency was more dominant in their life stories. They paid much attention to the success of their academic performance. If we focus on the perfectionists with negative tone, they usually showed a strong pursuit of agency, a sense of control and status, either in the way of avoiding or facing competition or in the way of compensating for the desire of love and relationships. However, why do the perfectionists of the latter case bear the characteristics of perfectionism? Based on the theory of self psychology (Kohut \& Wolf, 1978; Kohut, 1984), the lack of love affects the interaction between the self and its self objects, which leads to a damaged structure of the self-narcissistic (an grandiose or perfectionistic self).

Either using agency to compensate communion or conversely, using communion to compensate agency is an unhealthy mode. In the processing of coding, we found out that perfectionists with positive tone mostly experience a state of balance between agency and communion. So we suppose that only in a state of balance of agency and communion, a relatively healthy personality can be formed. In their life story, what they focused were not only themselves, but also on achieving satisfaction from helping and understanding others. For example, respondent $\mathrm{H}$ reported that he felt happy when he got or helped others achieve excellent research. Respondent $\mathrm{G}$ was glad to help others do something within his capability and kept his promises well.

This research also reveals some implications to psychological treatment on perfectionism. Regarding to the 
treatment of neurological disorders bearing perfectionistic personality, the author has some suggestions. Firstly, a notable life philosophy feature of perfectionists is black-or-white, which means they see things either totally good or totally bad. So it is important to integrate the good and the bad object. This integration can be improved by adjusting and analyzing the relationship between the counselor and the patient. Secondly, counselors could help patients do self-analysis or take part into the related workshop. Respondent I reported that he gained a lot from these forms of therapy. Meanwhile, the experience of emotional changing(such as fear and anxiety), the correlation between the emotion and events, and the consistency of the emotional response (e.g., positive tone, negative tone...) are very important. Thirdly, perfectionists with negative tone pay excessive attention to themselves. It can be concluded from the comparison between perfectionists with negative tone and positive tone. For example, respondent $\mathrm{G}$ and $\mathrm{H}$ showed their balance between agency and communion. They showed their tendency to help others in the analysis of themes (Code 7). So this pursuit for perfection is a healthy mode rather than the mode of avoiding failure.

There are some limitations in this study. First, the sample size is small and limited to the undergraduate students, which weakens the explanatory power of what we obtain from the present study. In addition, due to the large workload of qualitative research, there are still some aspects that need to best udied and analyzed further, e.g., specific scenes and the themes of the life story. Moreover, the cultural background is a key factor that has to be taken into consideration. In sum, the present study is only a pilot study and further studies should be conducted with a larger sample and diverse cultural background.

\section{References}

Ablard, K. E., \& Parker, W. D. (1997). Parents' achievement goals and perfectionism in their academically talented children. Journal of Youth and Adolescence, 26(6), 651-667. http://dx.doi.org/10.1023/A:1022392524554

Adler, A. (1956). Striving for superiority. In H. L. Ansbacher, \& R. Ansbacher (Eds.), The Individual Psychology of Alfred Adler: A Systematic Presentation in Selections from His Writings (pp. 101-125). New York, NY: Harper \& Row.

Ashby, J. S., \& Kottman, T. (1996). Inferiority as a distinction between normal and neurotic perfectionism. Individual Psychology, 52(3), 237-245.

Azizi, K., \& Besharat, M. A. (2011). The relationship between parental perfectionism and child perfectionism in a sample of Iranian families. 3rd World Conference on Educational Sciences, 2011, 15. http://dx.doi.org/10.1016/j.sbspro.2011.03.279

Baken, D. (1966). The duality of human existence: Isolation and communion in Western man. Boston, MA: Beacon Press.

Bauer, J., McAdams, D., \& Pals, J. (2008). Narrative identity and eudaimonic well-being. Journal of Happiness Studies, 9(1), 81-104. http://dx.doi.org/10.1007/s10902-006-9021-6

Baumrind, D. (1989). Rearing competent children. In W. Damon (Ed.), Child development today and tomorrow (pp. 349-378). San Francisco, CA: Josssey-Bass.

Black, J., \& Reynolds, W. M. (2013). Examining the relationship of perfectionism, depression, and optimism: Testing for mediation and moderation. Personality and Individual Differences, 54(3), 426-431. http://dx.doi.org/10.1016/j.paid.2012.10.012

Burns, D. (1980). The perfectionist's script for self-defeat. Psychology Today, 14(6), 34-52.

Carson, D. K., \& Runco, M. A. (1999). Creative problem solving and problem finding in young adults: Interconnections with stress, hassles, and coping abilities. Journal of Creative Behavior, 33(3), 167-190.

DiBartolo, P. M., Li, C. Y., \& Frost, R. O. (2008). How do the dimensions of perfectionism relate to mental health? Cognitive Therapy and Research, 32(3), 401-417. http://dx.doi.org/10.1007/s10608-007-9157-7

Eum, K., \& Rice, K. G. (2011). Test anxiety, perfectionism, goal orientation, and academic performance. Anxiety Stress and Coping, 24(2), 167-178. http://dx.doi.org/10.1080/10615806.2010.488723

Flett, G., Hewitt, P., \& Singer, A. (1995). Perfectionism and parental authority styles. Individual Psychology: The Journal of Adlerian Theory Research \& Practice, 51(1), 50-60.

Frost, R. O., Heimberg, R. G., Holt, C. S., Mattia, J. I., \& Neubauer, A. L. (1993). A comparison of two measures of perfectionism. Personality and Individual Differences, 14(1), 119-126. http://dx.doi.org/10.1016/0191-8869(93)90181-2 
Frost, R. O., Marten, P., Lahart, C., \& Rosenblate, R. (1990). The dimensions of perfectionism. Cognitive Therapy and Research, 14(5), 449-468. http://dx.doi.org/10.1007/BF01172967

Hermans, H. J. M., Kempen, H. J. G., \& Van Loon, R. J. P. (1992). The dialogical self: Beyond individualism and rationalism. American Psychologist, 47, 23-33. http://dx.doi.org/10.1037/0003-066X.47.1.23

Hewitt, P. L., \& Flett, G. L. (1991a). Dimensions of perfectionism in unipolar depression. Journal of Abnormal Psychology, 100(1), 98-101. http://dx.doi.org/10.1037/0021-843x.100.1.98

Hewitt, P. L., \& Flett, G. L. (1991b). Perfectionism in the self and social contexts: Conceptualization, assessment, and association with psychopathology. Journal of Personality and Social Psychology, 60(3), 456-470. http://dx.doi.org/10.1037/0022-3514.60.3.456

Horney, K. (1992). Our inner conflicts: A constructive theory of neurosis. New York, NY: Norton.

Johnson, D. P., \& Slaney, R. B. (1996). Perfectionism: Scale development and a study of perfectionistic clients in counseling. Journal of College Student Development, 37(1), 29-41.

Jones, K., Runco, M. A., Dorman, C., \& Freeland, D. C. (1997). Influential factors in artists' lives and themes in their artwork. Creativity Research Journal, 10(2-3), 221-228.

Kohut, H., \& Wolf, E. S. (1978). Disorders of the Self and Their Treatment-Outline. International Journal of Psycho-Analysis, 59, 413-425.

Mackinnon, S. P., Sherry, S. B., \& Pratt, M. W. (2013). The relationship between perfectionism, agency, and communion: A longitudinal mixed methods analysis. Journal of Research in Personality, 47(4), 263-271. http://dx.doi.org/10.1016/j.jrp.2013.02.007

Maslow, A. H. (1943). A theory of human motivation. Psychological Review, 50(4), 370-396. http://dx.doi.org/10.1037/h0054346

Maslow, A. H. (1970). Motication and Personality. New York: Harper \& Row.

McAdams, D. P. (1985). Power, intimacy and the life story: Personological inquiries into identity. New York, NY: Guilford Press.

McAdams, D. P. (1993). The stories we live by. Personal myths and the making of the self. New York: William Morrow and Company.

McAdams, D. P. (1996). Personality, modernity, and the storied self: A contemporary framework for studying persons. Psychological Inquiry, 7(4), 295-321.

McAdams, D. P. (2001). Coding autobiographical episodes for themes of agency and communication. Retrieved from http://www.sesp.northwestern.edu/docs/Agency_Communion01.pdf

McAdams, D. P. (2008). Personal narratives and the life story. In O. P. John, R. W. Robins, \& L. A. Pervin (Eds.), Handbook of personality: Theory and research (3rd ed., pp. 242-262). New York, NY: Guilford Press.

McAdams, D. P. (2011). Narrative identity. In S. J. Schwartz, K. Luyckx, \& V. L. Vignoles (Eds.), Handbook of identity theory and research (pp. 99-115). New York, NY: Springer.

McAdams, D. P., Anyidoho, N. A., Brown, C., Huang, Y. T., Kaplan, B., \& Machado, M. A. (2004). Traits and stories: Links between dispositional and narrative features of personality. Journal of Personality, 72(4), 761-784. http://dx.doi.org/10.1111/j.0022-3506.2004.00279.x

McAdams, D. P., Diamond, A., de St. Aubin, E., \& Mansfield, E. (1997). Stories of commitment: The psychosocial construction of generative lives. Journal of Personality and Social Psychology, 72(3), 678-694. http://dx.doi.org/10.1037/0022-3514.72.3.678

Moretz, M. W., \& Mckay, D. (2009). The role of perfectionism in obsessive-compulsive symptoms: "Not just right" experiences and checking compulsions. Journal of Anxiety Disorders, 23(5), 640-644. http://dx.doi.org/10.1016/j.janxdis.2009.01.015

Pacht, A. R. (1984). Reflections on perfection. American Psychologist, 39(4), 386-390. http://dx.doi.org/10.1037/0003-066x.39.4.386

Runco, M. A. (1985). Reliability and Convergent Validity of Ideational Flexibility as a Function of Academic-Achievement. Perceptual and Motor Skills, 61(3), 1075-1081.

Runco, M. A. (1986). The Discriminant Validity of Gifted Childrens Divergent Thinking Test-Scores. Gifted Child Quarterly, 30(2), 78-82. 
Sarbin, T. R. (1986). The narrative as root metaphor for psychology. In T. R. Sarbin (Ed.), Narrative psychology: The storied nature of human conduct (pp. 3-21). New York, NY: Praeger.

Sassaroli, S., Apparigliato, M., Bertelli, S., Boccalari, L., Fiore, F., Lamela, C., . . Ruggiero, G. M. (2011). Perfectionism as a mediator between perceived criticism and eating disorders. Eating and Weight Disorders-Studies on Anorexia Bulimia and Obesity, 16(1), E37-E44.

Sassaroli, S., Lauro, L. J. R., Ruggiero, G. M., Mauri, M. C., Vinai, P., \& Frost, R. (2008). Perfectionism in depression, obsessive-compulsive disorder and eating disorders. Behaviour Research and Therapy, 46(6), 757-765. http://dx.doi.org/10.1016/j.brat.2008.02.007

Stairs, A. M., Smith, G. T., Zapolski, T. C. B., Combs, J. L., \& Settles, R. E. (2012). Clarifying the Construct of Perfectionism. Assessment, 19(2), 146-166. http://dx.doi.org/10.1177/1073191111411663

Terry-Short, L. A., Owens, R. G., Slade, P. D., \& Dewey, M. E. (1995). Positive and negative perfectionism. Personality and Individual Differences, 18(5), 663-668. http://dx.doi.org/10.1016/0191-8869(94)00192-u

Tomkins, S. (1987). Script theory. In J. Arnoff, A. I. Rabin, \& R. A. Zucker (Eds.), The emergence of personality (pp. 147-216). New York, NY: Springer Publishing Company.

Weisinger, H., \& Lobsenz, N. (1981). Nobody's perfect. New York, NY: Warner Books.

Wu, K. D., \& Cortesi, G. T. (2009). Relations between perfectionism and obsessive-compulsive symptoms: Examination of specificity among the dimensions. Journal of Anxiety Disorders, 23(3), 393-400. http://dx.doi.org/10.1016/j.janxdis.2008.11.006

Zi, F. (2007). Developing the negative perfectionism questionnaire. China Journal of Health Psychology, 15(4), 340-344.

Zi, F. (2009). Developing the positive perfectionism questionnaire. Chinese Journal of Clinical Psychology, 4, 424-426.

\section{Note}

Note 1. Baken (1966) supposed that there are two fundamental modalities in the existence of living forms: agency and communion. He pointed out that agency is the existence of an organism as an individual, while communion is the participation of the individual in some larger organism of which the individual is a part of.

\section{Copyrights}

Copyright for this article is retained by the author(s), with first publication rights granted to the journal.

This is an open-access article distributed under the terms and conditions of the Creative Commons Attribution license (http://creativecommons.org/licenses/by/3.0/). 